\title{
Bladder cancer cell-secreted exosomal miR-21 activates the PI3K/AKT pathway in macrophages to promote cancer progression
}

\author{
FAN LIN，HU-BIN YIN，XIN-YUAN LI，GONG-MIN ZHU，WEI-YANG HE and XIN GOU
}

\author{
Department of Urology, The First Affiliated Hospital, Chongqing Medical University, Chongqing 400016, P.R. China
}

Received May 12, 2019; Accepted November 8, 2019

DOI: 10.3892/ijo.2019.4933

\begin{abstract}
Tumour-associated macrophages (TAMs) compose a major component of the tumour microenvironment and form in this microenvironment prior to cancer metastasis. However, the detailed mechanisms of TAM remodelling in the context of bladder cancer have not been clearly defined. The present study collected exosomes from the conditioned medium of human bladder T24 cancer cells. The effects of macrophages treated with exosomes derived from T24 cells on bladder cancer cell migration and invasion were analysed by Transwell assays. The expression levels of endogenous and exosomal microRNA-21 (miR-21) were examined by reverse transcription-quantitative PCR, while the expression level of the target protein was analysed by western blot analysis. Luciferase reporter plasmids and mutants were used to confirm direct targeting. The effects of miR-21 on bladder cancer cell migration and invasion were analysed by Transwell and Matrigel assays following miR-21 transfection. It was identified that exosomes derived from bladder cancer cells polarized THP-1 cell-derived macrophages into the M2 phenotype, and TAM-mediated pro-migratory and pro-invasive activity was determined. Moreover, it was found that miR-21 was highly expressed in exosomes derived from bladder cancer cells as well as in macrophages treated with exosomes. In addition, macrophages transfected with miR-21 exhibited M2 polarization and promoted T24 cell migratory and invasive ability. Mechanistically, exosomal miR-21 derived from bladder cancer cells inhibited phosphatase and tensin homolog activation of the PI3K/AKT signalling pathway in macrophages and enhanced STAT3 expression to promote M2 phenotypic polarization. The present results suggest that exosomal miR-21 can promote cancer progression by polarizing TAMs.
\end{abstract}

Correspondence to: Professor Xin Gou, Department of Urology, The First Affiliated Hospital, Chongqing Medical University, 1 Youyi Road, Yuzhong, Chongqing 400016, P.R. China

E-mail: gouxincq@163.com

Key words: bladder cancer, exosomes, microRNA, tumourassociated macrophages

\section{Introduction}

Bladder cancer is one of the most common types of urinary cancer. The incidence of bladder cancer has been steadily increasing and there was an estimated 81,190 new bladder cancer cases diagnosed in the USA in 2018 (1). Furthermore, the risk of recurrence and progression remains high (2). Therefore, there is an urgent need to find stable new biomarkers and to identify the mechanisms of bladder cancer progression in order to support targeted bladder tumour therapy (3).

Cells can communicate with adjacent cells or distant cells by secreting extracellular vesicles (EVs), which exist in a variety of sizes ranging between 100 and $1,000 \mathrm{~nm}$ in diameter. Exosomes are produced in EVs and secreted when the vesicles fuse with the cell membrane. Exosomes are carriers with diameters of $<150 \mathrm{~nm}$ and are rich in proteins, lipids, RNA and other components (4). As exosomes carry surface molecules, they can induce signal transduction through receptor-ligand interactions; alternatively, they can be internalized by endocytosis and/or phagocytosis and can even fuse with target cell membranes to deliver their contents into the cytoplasm (5). Therefore, exosomes derived from donor cells are capable of altering the physiological states of recipient cells. In particular, exosomes derived from non-tumour cells can promote adaptation of disseminated cancer cells to the external environment, thereby reflecting the occurrence of the dynamic changes in the metastatic microenvironment $(6,7)$.

Macrophages are one of the most abundant types of stromal cells found in the tumour microenvironment (TME). Macrophages can be induced to exhibit an immunological M1 phenotype that inhibits tumours or an M2 phenotype that promotes tumour inflammation/immunosuppression (8). Tumour-associated macrophages (TAMs), which are considered to be similar to M2 macrophages, promote tumour metastasis by enhancing tumour cell motility, promoting angiogenesis and degrading the extracellular basal layer (9). In recent years, TAMs have been extensively studied and are now considered to be important factors in tumour progression $(10,11)$. Several methods are used to study macrophages in vitro, among which evaluation of primary peripheral blood mononuclear cells and assessment of variations in differentiation among monocyte lines are the most common methods (12). TAM populations are commonly used to mimic the functions of macrophage populations because primary tissue-derived macrophages are 
difficult to grow and expand in vitro $(12,13)$. Currently, the driving force for the differentiation of TAMs remains largely unknown, and it is unclear whether tumour-derived exosomes are functionally essential for changes in the TME. The present study identified a microenvironmental mechanism that forms TAMs through exosome-mediated communication between cancer cells and immune cells.

\section{Materials and methods}

Cell culture. The human bladder cancer cell line T24 was a gift from the Molecular Tumour and Epigenetic Experiment of Chongqing Medical University (Chonqing, China). THP-1 human acute monocytic leukaemia cells were kindly provided by the Stem Cell Bank, Chinese Academy of Sciences. All cell lines were maintained in RPMI-1640 medium (cat. no. 10-040-CVR; Corning, Inc.) supplemented with $10 \%$ EV-depleted foetal bovine serum (FBS; cat. no. SA102.02; CellMax), $100 \mathrm{U} / \mathrm{ml}$ penicillin and $100 \mu \mathrm{g} / \mathrm{ml}$ streptomycin (cat. no. C0222; Beyotime Institute of Biotechnology), and bovine EV-depleted medium was obtained by overnight ultracentrifugation at $100,000 \mathrm{x} \mathrm{g}$ at $4^{\circ} \mathrm{C}$ (14). The cells were cultured at $37^{\circ} \mathrm{C}$ in a standard humidified incubator with $5 \% \mathrm{CO}_{2}$. All experiments were performed when the cells reached $70-80 \%$ confluency.

Macrophage differentiation. To generate M0 macrophages, monocytic THP-1 cells were cultured in complete medium (RPMI-1640 with 10\% EV-depleted FBS) at a relatively low cell density $\left(2.5 \times 10^{5}\right.$ cells $\left./ \mathrm{ml}\right)$ with $100 \mathrm{ng} / \mathrm{ml}$ phorbol 12-myristate 13-acetate (PMA; cat. no. P1585; Sigma-Aldrich; Merck KGaA) for $24 \mathrm{~h}$ for differentiation into resting (M0) macrophages (15).

Flow cytometry. Single-cell suspensions were stained with FITC anti-human CD11b and CD14 antibodies (1:20; cat. nos. 301329 and 301803, respectively; BioLegend, Inc.) for $30 \mathrm{~min}$ at $37^{\circ} \mathrm{C}$. FITC mouse IgG1 and IgG2a antibodies (1:20; cat. nos. 400109 and 400207; BioLegend, Inc.) were used to stain single cell suspensions for $30 \mathrm{~min}$ at $37^{\circ} \mathrm{C}$. These control antibodies were the isotype controls for CD11b and CD14, respectively, and were used as a reference in each experiment. In total, $\sim 1 \times 10^{5}$ events were collected for each sample with a Becton Dickinson FACS Calibur system (BD Biosciences) and FlowJo software 7.6.1 (FlowJo, LLC) was used for analysis.

Exosome isolation. According to a previously published protocol (16), exosomes were collected by differential ultracentrifugation under appropriately optimized conditions. Briefly, T24 cells were cultured for $48 \mathrm{~h}$ in complete RPMI-1640 medium containing $10 \%$ EV-depleted FBS. The conditioned medium was collected, centrifuged at $300 \mathrm{x}$ g for $10 \mathrm{~min}$ at $4^{\circ} \mathrm{C}$ to remove free cells and then centrifuged at $2,000 \times \mathrm{g}$ for $10 \mathrm{~min}$ at $4^{\circ} \mathrm{C}$ to remove dead cells. Next, centrifugation was performed at $10,000 \times \mathrm{g}$ for $30 \mathrm{~min}$ at $4^{\circ} \mathrm{C}$ to remove cell debris. The supernatant was collected and filtered through a $0.22-\mu \mathrm{m}$ filter (cat. no. SLGP033RB; EMD Millipore) to remove contaminating apoptotic bodies and microvesicles. Then, the clarified supernatant was ultracentrifuged at $100,000 \mathrm{x} \mathrm{g}$ for $70 \mathrm{~min}$ at $4^{\circ} \mathrm{C}$ to precipitate the exosomes.
The supernatant was carefully removed and stored at $-20^{\circ} \mathrm{C}$ as the non-exosome-conditioned medium (non-exo-CM), and the crude precipitate containing the exosomes was washed with $1 \mathrm{ml}$ PBS. Ultracentrifugation was performed again at $100,000 \mathrm{x} \mathrm{g}$ for $70 \mathrm{~min}$ at $4^{\circ} \mathrm{C}$. The supernatant was aspirated, and the exosome pellets were resuspended in $200 \mu \mathrm{l}$ PBS and stored at $-20^{\circ} \mathrm{C}$.

Transmission electron microscopy (TEM). For TEM, freshly isolated exosomes were used; these were diluted with nuclease-free water to maximize image quality. A $10-\mu 1$ suspension with exosomes was adsorbed onto a carbon-coated 200-mesh nickel grid for $10 \mathrm{~min}$ at room temperature, and then the excess was blotted with filter paper. The sample was negatively stained with $10 \mu \mathrm{l} 10 \%$ phosphotungstic acid (cat. no. P4006; Sigma-Aldrich; Merck KGaA) for $10 \mathrm{sec}$ at room temperature, and excess stain was removed with filter paper. The mesh was thoroughly dried before viewing. TEM sample preparation and imaging were performed at the Electron Microscopy Laboratory of Chongqing Medical University.

Nanoparticle tracking analysis (NTA). NTA assays were performed using a ZetaView PMX 110 (Particle Metrix) and its corresponding software (ZetaView 8.02.28; Particle Metrix) (17,18). For NTA, exosomes were diluted in 1x PBS, and the resuspension volumes and dilution factors were used to calculate the total number of isolated exosomes. A 10- $\mu 1$ sample was transferred to $40 \mathrm{ml}$ distilled water and resuspended. The suspension was filtered through a 450-nm filter to separate the exosomes from the larger particles, and the resulting filtered suspension was used for particle measurement. Samples were taken at 11 different locations, and two cycles of readings were performed at each location. After automatically analysing all locations and removing any anomalous locations, the mean, median, diameter size and sample concentration were calculated using optimized machine software. The data obtained with the ZetaView instrument were analysed using the corresponding software ZetaView 8.02.28.

Exosome labelling and tracking. For the exosome uptake experiment, exosomes were labelled with a PKH67 Fluorescent Cell Ligation kit (Sigma-Aldrich; Merck KGaA) according to the manufacturer's instructions. The exosomes were then washed with $0.5 \%$ BSA/PBS (cat. no. P0007; Beyotime Institute of Biotechnology) to remove excess dye. The labelled exosomes were again ultracentrifuged at 100,000 x g for $1 \mathrm{~h}$ at $4^{\circ} \mathrm{C}$ to remove residual dye; then, the exosomes (at a concentration of $10 \mu \mathrm{g} / \mathrm{ml}$ ) were incubated with macrophages at $37^{\circ} \mathrm{C}$ for $8 \mathrm{~h}$ in the dark. The cell nuclei and cytoskeleton were separately stained with DAPI (cat. no. C1005; Beyotime Institute of Biotechnology) for $5 \mathrm{~min}$ at room temperature and F-actin (cat. no. KA4118; AmyJet Scientific) for $30 \mathrm{~min}$ at room temperature and then examined by laser scanning confocal microscopy (magnification, x800).

ELISA. Conditioned medium was separately collected from the control (macrophages cultured in the normal medium), non-exo-CM-treated (macrophages cultured in the non-exosome-conditioned medium) and exo-treated (macrophages treated with $10 \mu \mathrm{g} / \mathrm{ml}$ exosomes) groups, centrifuged 
at $1,000 \mathrm{xg}$ for $5 \mathrm{~min}$ at $4^{\circ} \mathrm{C}$, and stored at $-20^{\circ} \mathrm{C}$ until further analysis. Subsequently, IL-10 and IL-12 (p70) expression levels in the conditioned medium were quantified using ELISA kits (cat. nos. EK0416 and EK0421, respectively; Wuhan Boster Biological Technology, Ltd.) according to the manufacturer's instructions.

MicroRNA (miRNA or miR) transfection. Macrophages were transfected with miR-21-5p mimics, miR-21-5p inhibitor, mimic negative control (NC) or inhibitor NC (Shanghai GenePharma Co. Ltd.) using Lipofectamine ${ }^{\circledR} 2000$ (cat. no. 11668019; Invitrogen: Thermo Fisher Scientific, Inc.) at a final concentration of $100 \mathrm{nM}$, and the same conditions were applied for each transfection experiment. The efficiency of cell transfection was assessed by reverse transcription-quantitative PCR (RT-qPCR) after 48 h. Treatment with SF1670 (cat. no. S7310; Selleck Chemicals; 500 or $1 \mu \mathrm{M}$ ) for $24 \mathrm{~h}$ at $37^{\circ} \mathrm{C}$ was employed to inhibit phosphatase and tensin homolog (PTEN) after transfecting cells with miR-21-5p inhibitor. The sequences of mimic, inhibitor and negative controls were as follows: miR-21-5p mimic, 5'-UAGCUUAUCAGACUGAUG UUGA-3'; miR-21-5p inhibitor, 5'-CAGUACUUUUGUGUA GUACAA-3'; mimic negative control, 5'-UUCUCCGAACGU GUCACGUTT-3'; and inhibitor negative control, 5'-CAGUAC UUUUGUGUAGUACAA-3'.

Co-culture. For experiments involving co-culture of T24 cells and M0 macrophages, T24 cells were seeded onto $0.4 \mu \mathrm{m}$ pore size Transwell culture inserts (cat. no. 3450; Corning, Inc.) and transfected with $\mathrm{NC}$ or miR-21-5p inhibitor. After $24 \mathrm{~h}$, the inserts were transferred to dishes seeded with M0 macrophages and co-cultured for $24 \mathrm{~h}$.

Luciferase reporter assay. The miR-21-5p target gene, PTEN, was predicted using TargetScan software (version 7.2; http://www.targetscan.org/). These sequence of the wild-type miR-21 binding site on PTEN and a binding site mutant sequence were inserted into pmirGLO vectors (Shanghai GenePharma Co., Ltd.). Lipofectamine ${ }^{\circledR} 2000$ was then used for transfection of the cells, which were seeded in 6-well plates for $24 \mathrm{~h}$. According to the manufacturer's instructions, luciferase activity was measured using a dual luciferase reporter gene assay kit (cat. no. E1910; Promega Corporation). Renilla luciferase activity was used to normalize to firefly luciferase activity.

Migration and invasion assays. Cell migration and invasion assays were performed on 24-well Transwell cell culture chambers with $8-\mu \mathrm{m}$ wells pre-coated or not pre-coated with Matrigel basement membrane gel (cat. no. 354234; Corning, Inc.). T24 cells ( $8 \times 10^{4}$ cells) in RPMI-1640 medium were plated into the upper chambers with or without Matrigel (40 $\mu \mathrm{l} /$ well). Each different cell supernatant (from T24 cells, untreated macrophages, non-exo-CM-treated macrophages, exo-treated macrophages, negative control macrophages, miR-21-5p mimic-transfected macrophages or miR-21-5p inhibitor-transfected macrophages) was collected, diluted with fresh FBS media (RPMI-1640 with 10\% FBS) (1:1), and plated into each lower chamber. For migration assays, T2 4 cells incubated at $37^{\circ} \mathrm{C}$ for $8 \mathrm{~h}$. For invasion assays, the incubation time was $24 \mathrm{~h}$. The membranes were collected and stained with $0.5 \%$ crystal violet (cat. no. C0121; Beyotime Institute of Biotechnology) for $15 \mathrm{~min}$ at room temperature. Migrating and invading cells were observed under an optical microscope (magnification, x100). Five fields of view were randomly selected to calculate the number of cells that migrated and invaded.

$R T-q P C R$. Total RNA was isolated from cells and exosomes using TRIzol (cat. no. 15596026; Thermo Fisher Scientific, Inc.) according to the manufacturer's protocol. RNA was quantified using a Nanodrop ND-1000 (Thermo Fisher Scientific, Inc.). RT was carried out using a PrimeScript ${ }^{\mathrm{TM}}$ RT Reagent kit with gDNA Eraser (Perfect Real Time; cat. no. RR047A; Takara Bio, Inc.). qPCR was performed on a CFX96 Real-Time PCR Detection system (Bio-Rad Laboratories, Inc.) using TB Green Premix Ex Taq II (cat. no. RR820A; Takara Bio, Inc.), and the expression of mRNA or miRNA was normalized to $\beta$-actin or U6, respectively. The thermocycling parameters were as follows: i) initial denaturation at $95^{\circ} \mathrm{C}$ for $30 \mathrm{sec}$; ii) 40 cycles of denaturation at $95^{\circ} \mathrm{C}$ for $5 \mathrm{sec}$ and $60^{\circ} \mathrm{C}$ for $30 \mathrm{sec}$; and (3) annealing/extension at $65^{\circ} \mathrm{C}$ for $5 \mathrm{sec}$ with a $0.5^{\circ} \mathrm{C}$ increase for each repetition $\left(60\right.$ cycles to $\left.95^{\circ} \mathrm{C}\right)$. The results were analysed using the $2^{-\Delta \Delta C q}$ method (19). All primers are listed in Table I.

Western blot analysis. Cells and exosomes were lysed with RIPA buffer (cat. no. P0013B; Beyotime Institute of Biotechnology). A BCA protein assay kit (cat. no. P0010; Beyotime Institute of Biotechnology) was used to detect protein concentrations, and a $12 \%$ sodium dodecyl sulfate-polyacrylamide gel was applied for total protein $(30 \mu \mathrm{g})$ separation. The proteins in the gel were transferred to a $0.45-\mu \mathrm{M}$ pore size PVDF membrane (cat. no. IPVH00010; EMD Millipore) via wet electrophoretic transfer. The western blots were blocked with skim milk powder for $1 \mathrm{~h}$ at room temperature and incubated overnight at $4^{\circ} \mathrm{C}$ with anti-CD9 (cat. no. ab92726; Abcam), anti-CD63 (cat. no. ab134045; Abcam), anti-tumour susceptibility gene 101 (TSG101; cat. no. ab125011; Abcam), anti-PI3 kinase p85 (cat. no. 4257T; Cell Signalling Technology, Inc.), anti-PTEN (cat. no. 9559T; Cell Signalling Technology, Inc.), anti-AKT (cat. no. 4691T; Cell Signalling Technology, Inc.), anti-phosphorylated (p)-AKT (cat. no. 2965T; Cell Signalling Technology, Inc.), anti-STAT3 (cat. no. 4904T; Cell Signalling Technology, Inc.) and anti-p-STAT3 (cat. no. 9145T; Cell Signalling Technology, Inc.) antibodies, all diluted to 1:1,000. An anti-b-actin antibody (cat. no. 4970S; 1:2,000; Cell Signalling Technology, Inc.) and anti-GAPDH (cat. no. 10494-1-AP; 1:20,000; ProteinTech Group, Inc.) were used as internal loading controls. Following antibody incubation, the protein bands were washed three times with TBS-Tween 20 on an orbital shaker in $10 \mathrm{~min}$ intervals. Subsequently, the membranes were incubated with a horseradish peroxidase-conjugated secondary antibody (cat. no. A0208; 1:3,000; Beyotime Institute of Biotechnology) for $1 \mathrm{~h}$ at room temperature and then developed using an electrochemiluminescence western blot detection reagent (cat. no. WBKLS0010; EMD Millipore). Fusion FX Spectra software (version 7; Vilber) was used to detect the bands. The protein expression levels in the various groups were compared 
Table I. Primers used for reverse transcription-quantitative PCR.

\begin{tabular}{ll}
\hline Gene & \multicolumn{1}{c}{ Primer sequence } \\
\hline miR-21-5p & Forward: 5'-ACACTCCAGCTGGGTAGCTTATCAGACTGA-3' \\
PTEN & Reverse: 5'-TGGTGTCGTGGAGTCG-3' \\
& Forward: 5'-TGGATTCGACTTAGACTTGACCT-3' \\
IL-10 & Reverse: 5'-GGTGGGTTATGGTCTTCAAAAGG-3' \\
& Forward: 5'-GACTTTAAGGGTTACCTGGGTTG-3' \\
TGF- $\beta$ & Reverse: 5'-TCACATGCGCCTTGATGTCTG-3' \\
$\beta$-actin & Forward: 5'-GGTACCTGAACCCGTGTTGCT-3' \\
& Reverse: 5'-TGTTGCTGTATTTCTGGTAACAGCTC-3' \\
U6 & Forward: 5'-GTCTTCCCCTCCATCGTG-3' \\
& Reverse: 5'-AGGGTGAGGATGCCTCTCTT-3' \\
& Forward: 5'-CTCGCTTCGGCAGCACA-3' \\
& Reverse: 5'-AACGCTTCACGAATTTGCGT-3'
\end{tabular}

miR-21-5p, microRNA-21-5p; PTEN, phosphatase and tensin homolog.

with those in the control group based on the relative intensities of the bands.

Statistical analysis. Three independent experiments were performed and the experimental results are shown as the mean \pm standard deviation. The data were compared using Student's t-test for two groups. The differences among multiple groups were assessed using one-way ANOVA followed by a post-hoc Bonferroni test. $\mathrm{P}<0.05$ was considered to indicate a statistically significant difference. All statistical analyses were performed with SPSS statistical software 19.0 (IBM Corp.).

\section{Results}

Morphological characteristics of THP-1 cells after differentiation. To obtain M0 macrophages, PMA was used to induce polarization of THP-1 cells as described previously $(15,20)$. Macrophage-like morphological changes were observed in THP-1 cells after stimulation with PMA for $24 \mathrm{~h}$ (Fig. 1A). The cytoplasmic volume was increased in human monocyte-derived macrophages compared with monocytes. Compared with no treatment, PMA treatment of THP-1 cells results in a more mature phenotype with lower proliferation rates, higher adherence levels and increased expression of cell surface markers (13). The present study analysed the expression levels of CD11b and CD14, as CD11b and CD14 are reported to be common markers for the differentiation of monocytes into macrophages $(15,20)$. In the absence of any stimulation, 19.44 and $69.46 \%$ of cultured THP-1 cells were positive for CD11b and CD14, respectively. After treatment with PMA, marked increases in the numbers of CD11b- and CD14-positive cells (65.46 and 90.72\%) were observed (Fig. 1B). These results showed that M0 macrophages were successfully obtained from THP-1 cells and could be used in subsequent experiments, which was consistent with other studies $(21,22)$.

Identification of exosomes derived from $\mathrm{T} 24$ cells and uptake of the exosomes in macrophages. T24 is the most typically used and representative cell line model in bladder cancer research, with characteristics of a short generation time (19 h), high grade, and highly aggressive and metastatic potential. Therefore, T24 cells were selected as the representative cell line for subsequent research. Exosomes can regulate the TME through the transfer of functional small RNAs or proteins (23). To confirm whether exosomes derived from T24 cells uptake into macrophages, exosomes were first collected from conditioned medium of T24 cells. TEM revealed that the purified exosomes had a cup-shaped morphology (Fig. 2A). NTA revealed that the diameters of the particles were within the expected range for exosomes $(40-150 \mathrm{~nm})$ and that the particles expressed the currently known exosomal markers CD9, CD63 and TSG101, consistent with the defined features of exosomes (Fig. 2B and C). To evaluate the biological interactions between exosomes derived from T24 cells and immune cells, fluorescently labelled exosomes were cultured with macrophages. After $8 \mathrm{~h}$ of incubation, confocal microscopy revealed the presence of stained exosomes in the cytoplasm of macrophages (Fig. 2D).

T24 cell-derived exosomes activate a TAM-like macrophage phenotype that can promote migration and invasion of T24 cells. To determine whether T24 cell-derived exosomes are capable of promoting M2 macrophage polarization, the expression of markers typical of the M2 phenotype was examined. Commonly used cytokine markers indicating macrophage polarization towards the M2 phenotype include IL-10 and transforming growth factor $\beta$ (TGF- $\beta$ ) (24). In addition, a non-exo-CM-treated group was used to observe the effect of substances outside exosomes on M2 polarization of macrophages. RT-qPCR showed that the mRNA levels of IL-10 and TGF- $\beta$ were significantly upregulated in exo-treated macrophages compared with control macrophages, while the levels in non-exo-CM-treated macrophages did not appear significantly altered (Fig. 3A). M2 macrophages are defined as having an in vitro phenotype of low IL-12 expression and high IL-10 expression (25). These results were further confirmed 
A

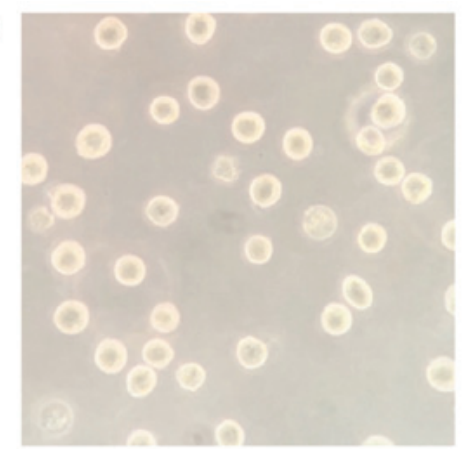

THP-1

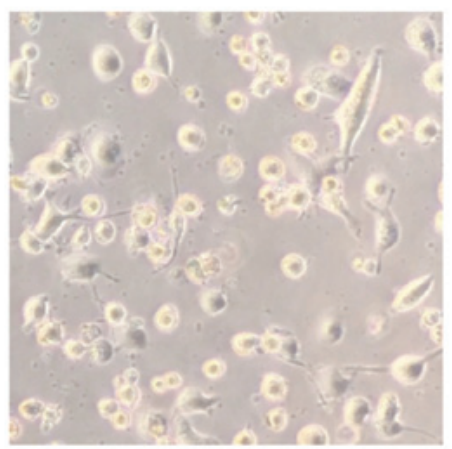

THP-1+PMA
B
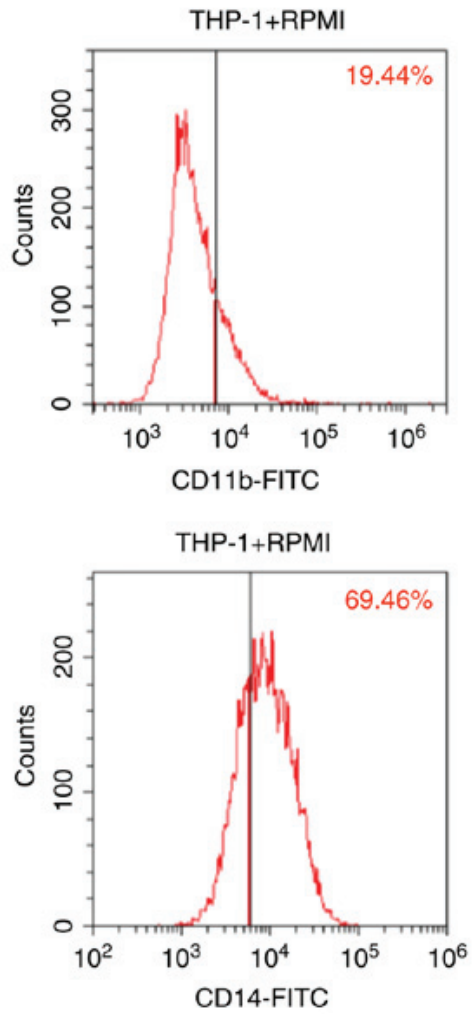

THP-1+PMA
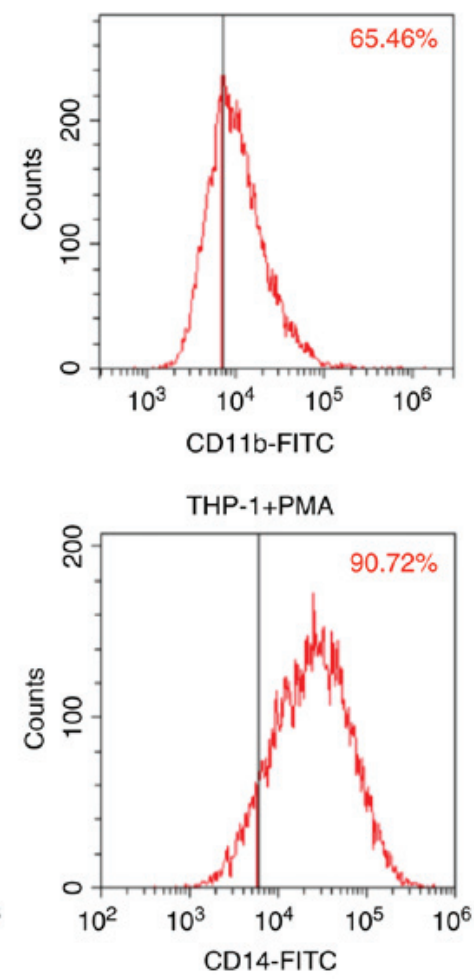

Figure 1. Characterization of PMA-treated THP-1 cells. (A) Morphological changes in THP-1 cells caused by PMA treatment. THP-1 cells were treated with $100 \mathrm{ng} / \mathrm{ml}$ PMA for $24 \mathrm{~h}$ for differentiation into resting macrophages. Magnification, x100. (B) Flow cytometry characterization of macrophages derived from THP-1 cells stimulated with PMA; CD11b and CD14 are specific markers of macrophages. PMA, phorbol 12-myristate 13-acetate.

using ELISA, which revealed the levels of IL-10 and IL-12 protein secreted into the macrophages supernatant (Fig. 3B). To further investigate the effects of exo-treated macrophages on cancer cell migration and invasion in vitro, macrophages were treated with exosomes $(10 \mu \mathrm{g} / \mathrm{ml})$ or non-exo-CM for $24 \mathrm{~h}$. Migration and invasion assays both revealed significant increases in the numbers of migrated and invasive T2 4 cells after incubation of the T24 cells with conditioned medium from exo-treated macrophages (Fig. 3C). These results suggested that T24 cell-derived exosomes promoted macrophage polarization toward the M2 phenotype, thereby enhancing T24 cell migratory and invasive ability. In addition, the substances outside exosomes do not participate in M2 differentiation.

miR-21 loaded in T24 cell-derived exosomes promotes M2 differentiation. Exosomes contain biologically active molecules that are involved in intercellular communication. Previous studies have shown that miR-21 is highly expressed in bladder cancer and stromal cells and is closely related to tumour progression (26). To elucidate whether miR-21 is also highly expressed in exosomes derived from bladder cancer cells (T24 cells), the expression of miR-21 was examined by RT-qPCR. The results showed that the expression of miR-21 in T24 cell-derived exosomes was significantly higher than that in parental cells (Fig. 4A). It was then examined whether tumour-derived exosomes could deliver miR-21 to macrophages. As shown in Fig. 4B, the level of miR-21 was higher in macrophages treated with T24 cell-derived exosomes compared with in untreated macrophages. To determine whether T24 cell-derived miR-21 could be directly transferred from bladder cancer cells to macrophages and affect macrophage polarization, a co-culture experiment was designed in which macrophages were co-cultured with T24 cells. RT-qPCR analysis of miR-21 was performed on the recipient cells. The level of miR-21 was higher in macrophages co-cultured with T24 cells than in macrophages (Fig. S1A). Compared with the control, macrophages co-cultured with T24 cells exhibited significantly higher expression of IL-10 and TGF- $\beta$ (Fig. S1B). The results suggested that co-culture with $\mathrm{T} 24$ cells promoted macrophage polarization toward the M2 phenotype. The present study then co-cultured macrophages with T24 cells that were transiently transfected with a miR-21-5p inhibitor (anti-miR-21-5p T24 cells). The results showed that miR-21 expression levels were significantly lower in macrophages co-cultured with anti-miR-21-5p T24 cells compared with those co-cultured with T24 cells (Fig. 4C). Furthermore, the mRNA levels of IL-10 and TGF- $\beta$ were significantly downregulated in macrophages co-cultured with anti-miR-21-5p T24 cells compared with those co-cultured with T24 cells (Fig. 4D). The results showed that co-culture with anti-miR-21-5p T24 cells inhibited M2 phenotypic polarization, indicating that $\mathrm{T} 24$ cell-derived miR-21 was a key factor inducing macrophage polarization in thus co-culture system.

The aforementioned data raise the question of whether upregulation of endogenous miR-21 can polarize macrophages toward the M2 phenotype. To answer this question, PMA-treated macrophages were transiently transfected with miR-21-5p mimics or miR-21-5p inhibitor, and miR-21 expression levels were evaluated by RT-qPCR. As presented in Fig. 4E, miR-21 transcript levels were significantly altered in macrophages transfected with miR-21-5p mimics or miR-21-5p 


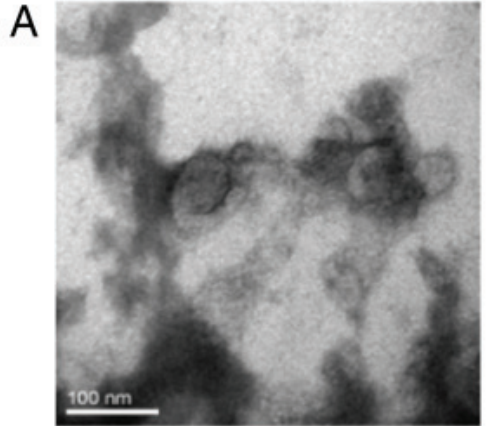

B
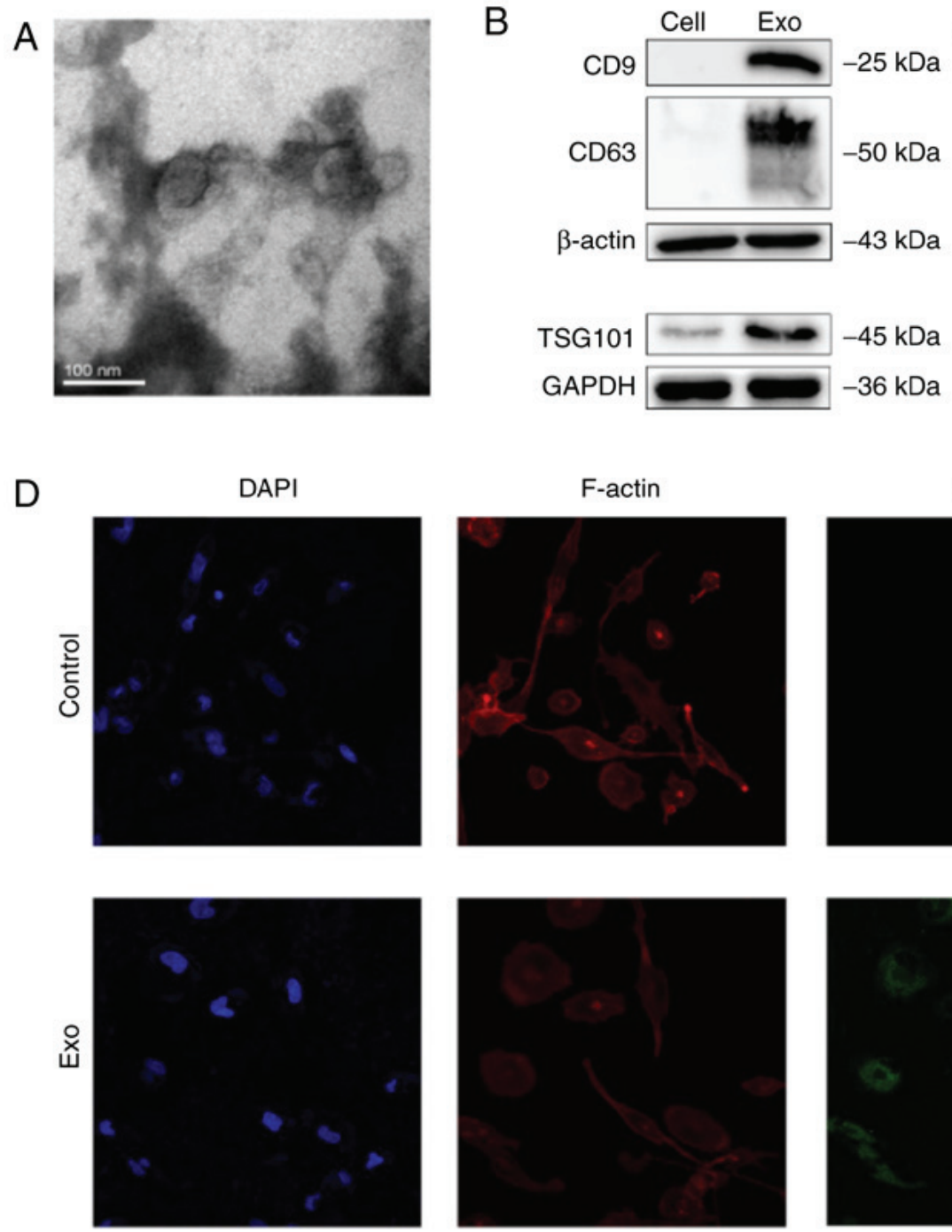
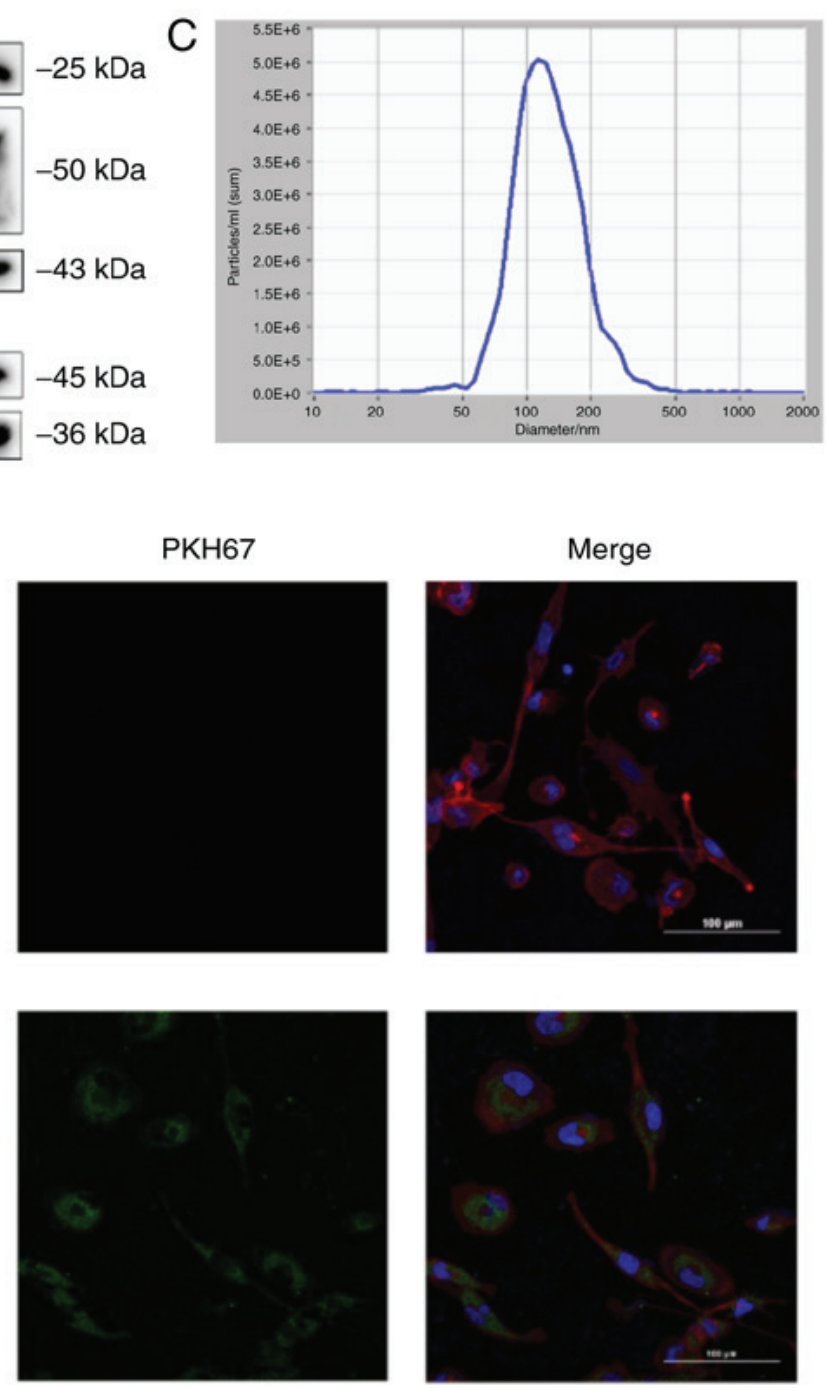

Figure 2. Characterization of T24 cell-derived exosomes and internalization of the exosomes into immune cells. (A) Representative TEM micrograph of exosomes derived from T24 cells. (B) Western blot analysis of the exosomal proteins CD9, CD63 and TSG101 in exosomes derived from T24 cells. (C) NTA of T24 cell-derived exosomes isolated by ultracentrifugation. (D) PKH67-labelled exosomes derived from T24 cells were shown to be taken up and internalized into the cytoplasm of macrophages under a confocal microscope. Representative images are shown. Scale bar, $100 \mu \mathrm{m}$. TEM, transmission electron microscopy; TSG101, tumour susceptibility gene 101; NTA, nanoparticle tracking analysis; Exo, exosome.

inhibitor. Compared with the mimics control, transfection of macrophages with miR-21-5p mimics significantly upregulated the expression of IL-10 and TGF- $\beta$ (Fig. 4F). Transfection of macrophages with miR-21-5p inhibitor did not significantly decrease the expression of M2 markers (IL-10 and TGF- $\beta$ ) (Fig. 4G). It was identified that upregulation of miR-21 in macrophages can polarize macrophages toward the M2 phenotype, while M2 phenotypic polarization did not occur in macrophages transfected with miR-21-5p inhibitor. Therefore, according to the results of the aforementioned experiments, a conclusion can be made that miR-21 loaded in T24-derived exosomes can promote M2-differentiation.

miR-21-5p mimics promote T24 cell migration and invasion by inducing M2 macrophage polarization. Furthermore, the effect of miR-21 expression in macrophages on T24 cells migration and invasion was investigated. Transwell and Matrigel assays showed that transfection of macrophages with miR-21-5p mimics significantly increased the migration and invasion of T24 cells
(Fig. 5A). Compared with control macrophages and macrophages transfected with a control inhibitor, miR-21 inhibitor-transfected macrophages showed significant reductions in the migratory and invasive ability of T24 cells (Fig. 5B). Therefore, enhancing miR-21 expression may enable macrophages to promote the migratory and invasive ability of T24 cells.

PTEN is suppressed by upregulation of miR-21 in macrophages. To elucidate the mechanism by which miR-21 mediates M2 polarization, potential miR-21 targets were searched using the computational prediction program TargetScan. PTEN deficiency has been found to facilitate M2 macrophage differentiation in a murine liver partial warm ischaemia model (27). Therefore, the present study focused on PTEN, a predicted miR-21 target gene (Fig. 6A). Dual luciferase reporter assays were performed to examine the direct interaction between miR-21 and the 3'-untranslated region (3'-UTR) of PTEN. The PTEN 3'-UTR downstream of a firefly luciferase reporter was cloned and it was identified that intact miR-21 downregulated 

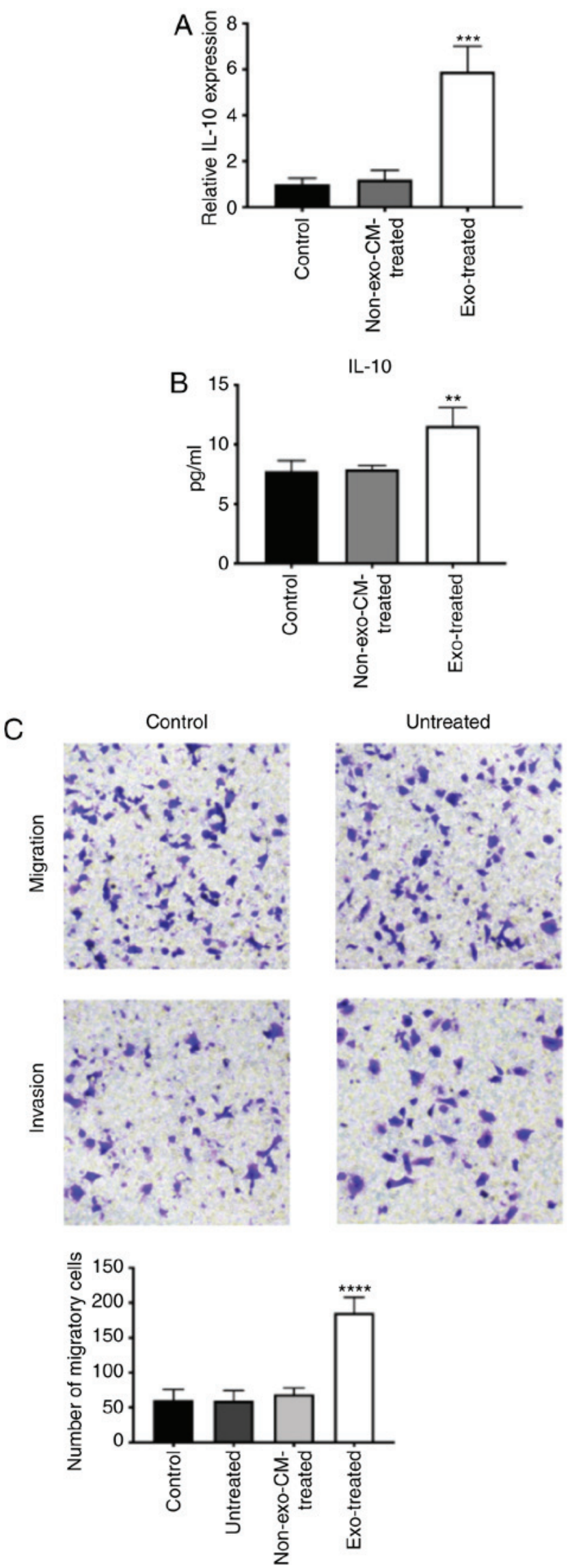
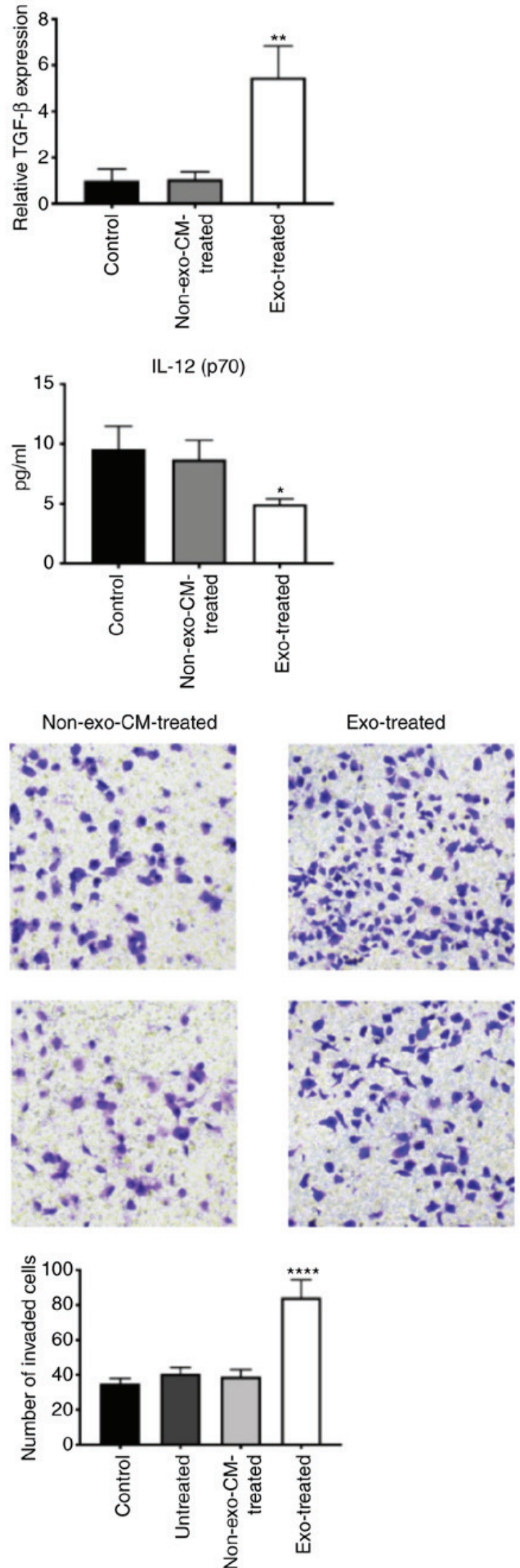

Figure 3. Exosomes derived from T24 cells induce polarization toward M2 macrophages and can promote bladder cancer cell migration and invasion. (A) RT-qPCR detection of IL-10 and TGF- $\beta$ mRNA expression in control, non-exo-CM-treated macrophages and exo-treated macrophages. (B) IL-10 and IL-12 (p70) levels measured by ELISA. (C) Migration and invasion assays of T24 cells cultured with supernatants from control, untreated, non-exo-CM-treated or exo-treated macrophages. Magnification, $\mathrm{x} 100 . \mathrm{n}=3 .{ }^{*} \mathrm{P}<0.05,{ }^{* *} \mathrm{P}<0.01,{ }^{* * * *} \mathrm{P}<0.001,{ }^{* * * * *} \mathrm{P}<0.01$ vs. control group. RT-qPCR, reverse transcription-quantitative PCR; non-exo-CM, non-exosome-conditioned medium; exo, exosome. 

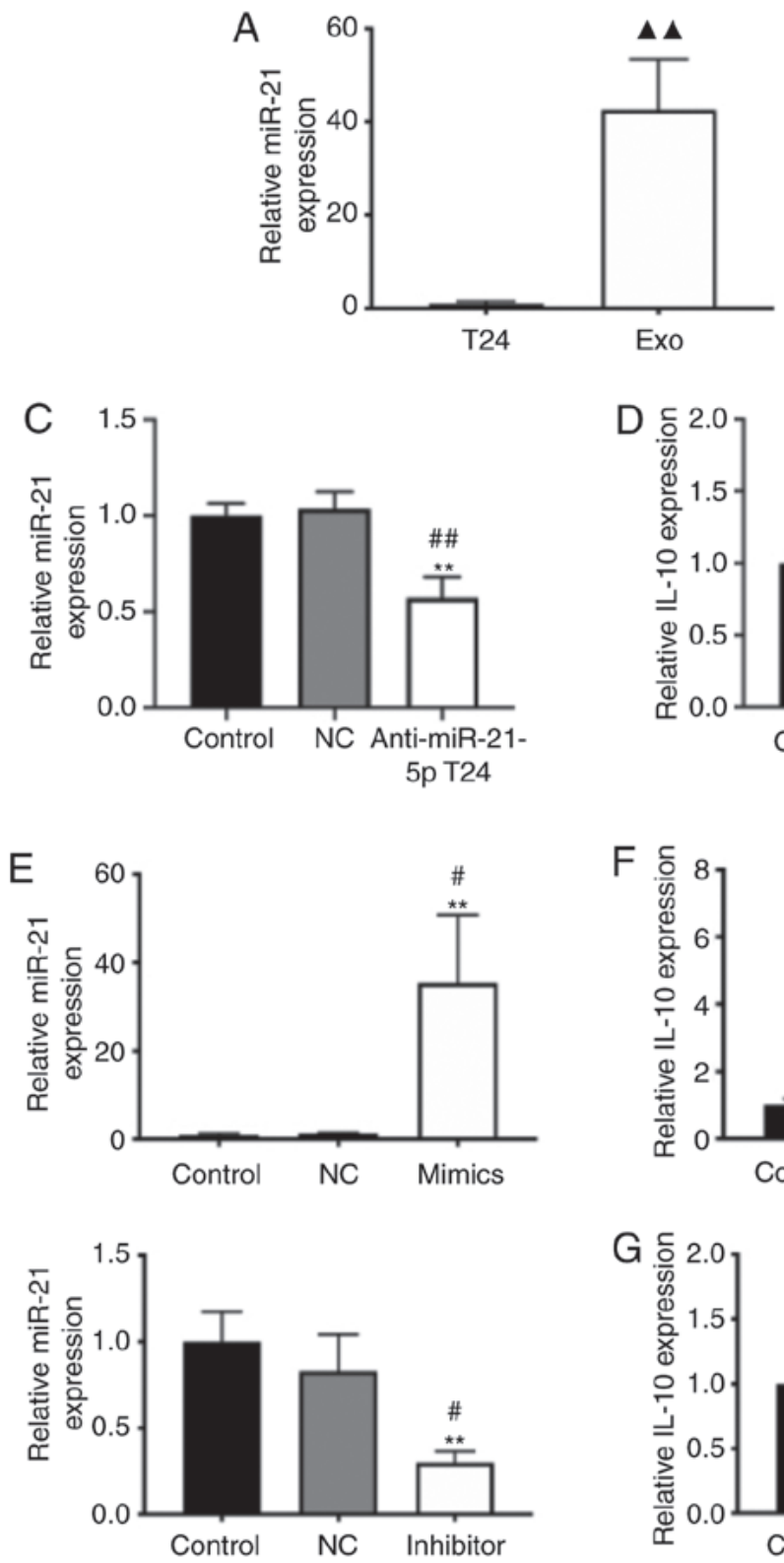
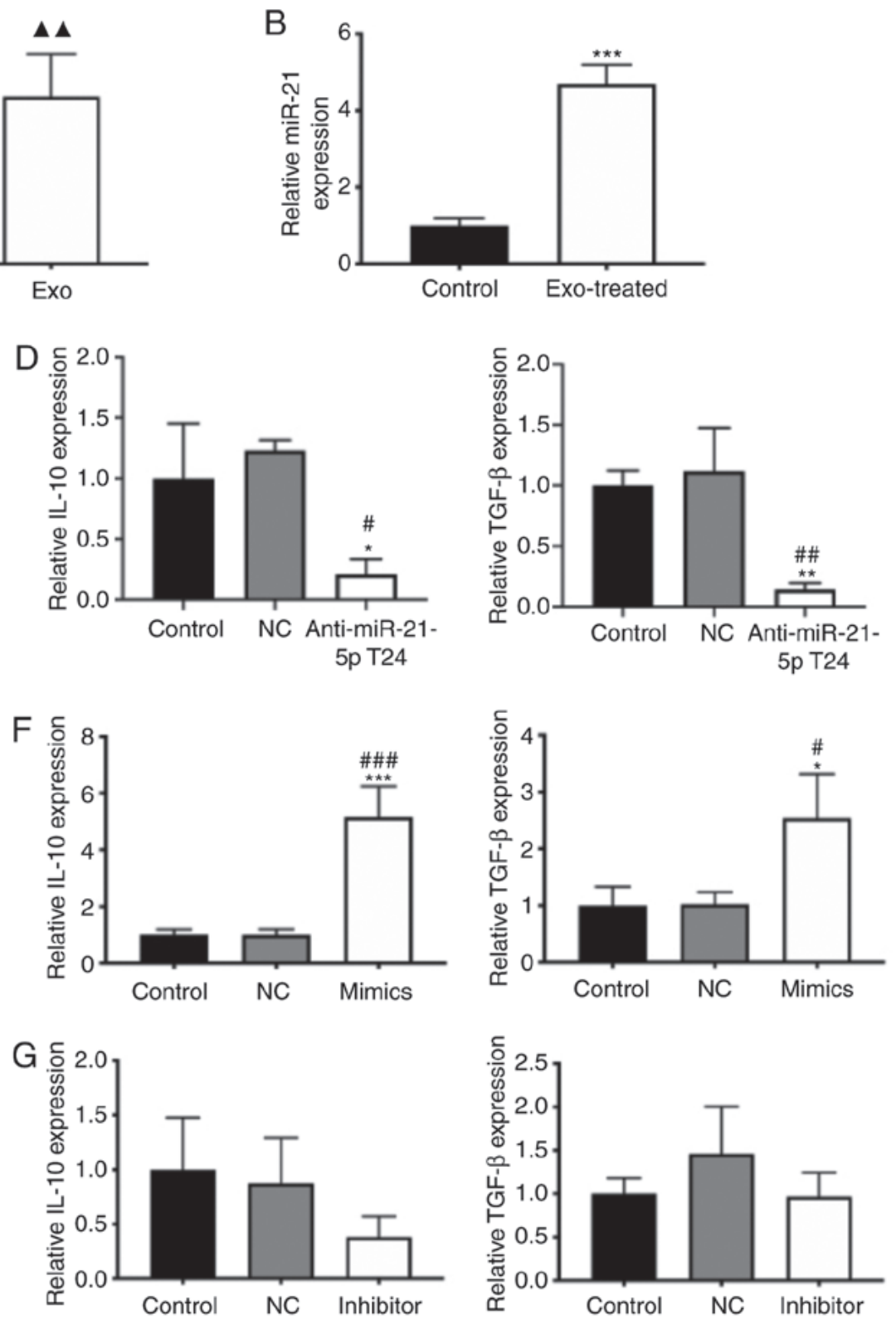

Figure 4. miR-21 is enriched in T24 cell-derived exosomes and is associated with M2 macrophage polarization. (A) Relative miR-21 expression in T24 cells and exosomes. (B) Relative miR-21 expression in macrophages treated with PBS or exosomes. (C) Relative miR-21 expression in macrophages co-cultured with T24 cells or anti-miR-21-5p T24 cells. (D) mRNA levels of IL-10 and TGF- $\beta$ in macrophages co-cultured with T24 cells or anti-miR-21-5p T24 cells. (E) miR-21 levels of macrophages transfected with miR-21-5p mimics or miR-21-5p inhibitor. (F) mRNA levels of IL-10 and TGF- $\beta$ in macrophages transfected with miR-21-5p mimics. (G) mRNA levels of IL-10 and TGF- $\beta$ in macrophages transfected with miR-21-5p inhibitor. $n=3$. ${ }^{\wedge} \mathrm{P}<0.01 \mathrm{vs}$. T24 group. ${ }^{*} \mathrm{P}<0.05,{ }^{* *} \mathrm{P}<0.01,{ }^{* * *} \mathrm{P}<0.001$ vs. control group. ${ }^{\#} \mathrm{P}<0.05,{ }^{\# \#} \mathrm{P}<0.01,{ }^{\# \#} \mathrm{P}<0.001$ vs. NC group. miR-21, microRNA-21; exo, exosome; Control, macrophages co-cultured with T24 cells or macrophages; NC, macrophages co-cultured with T24 cells transfected with the appropriate negative control or macrophages transfected with negative control; anti-miR-21-5p T24, macrophages co-cultured with T24 cells transfected with a miR-21-5p inhibitor; Mimics, macrophages transfected with miR-21-5p mimics; Inhibitor, macrophages transfected with miR-21-5p inhibitor.

the activity of the resulting reporter construct (Fig. 6B). When a mutant PTEN 3'-UTR with a disrupted miR-21 binding site was introduced, this downregulation was significantly reversed (Fig. 6B). The mRNA levels of PTEN were also determined using RT-qPCR, which revealed that they were lower in the exo-treated group compared with in the untreated group (Fig. 6C). RT-qPCR analysis showed that PTEN gene expression was significantly decreased in macrophages transfected with miR-21-5p mimics but significantly increased in macrophages transfected with miR-21-5p inhibitor (Fig. 6D). Furthermore, the recently developed PTEN-specific inhibitor
SF1670 was used to observe the role of the PTEN-mediated pathway in regulating macrophage polarization (28). The inhibitory effect of SF1670 was tested over $24 \mathrm{~h}$ at 500 and $1 \mu \mathrm{M}$ concentrations by western blotting, which revealed that SF1670 could inhibit the expression of PTEN in macrophages transfected with miR-21-5p inhibitor (Fig. 6E). In addition, SF1670 treatment at the $1 \mu \mathrm{M}$ concentration significantly increased the expression of M2 markers in miR-21 inhibitor-transfected macrophages (Fig. 6F). These results indicate that PTEN is a direct target gene by which miR-21 induces M2 differentiation. 
A
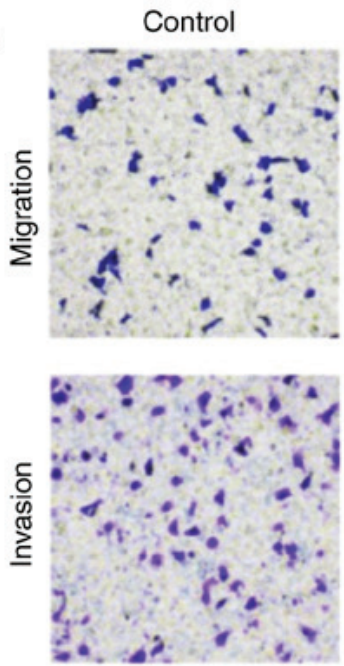

B
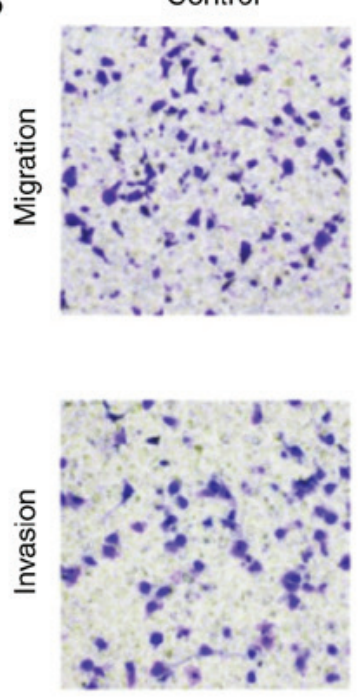
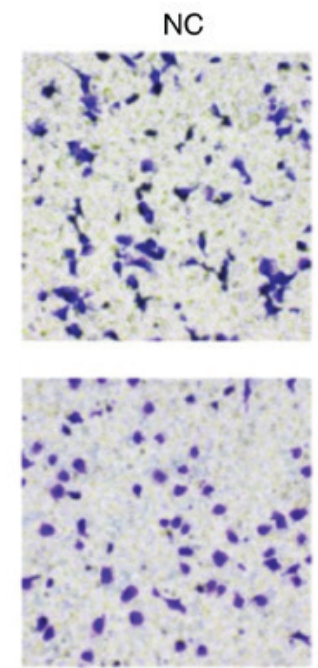

NC
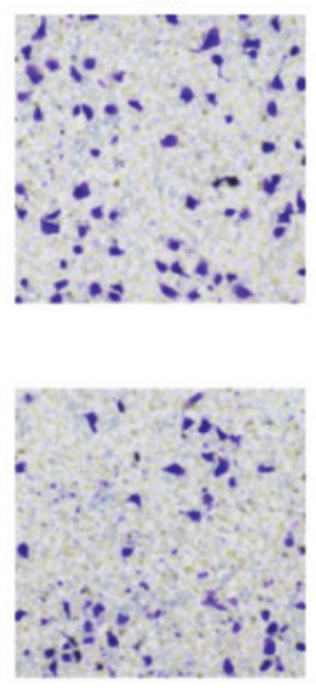
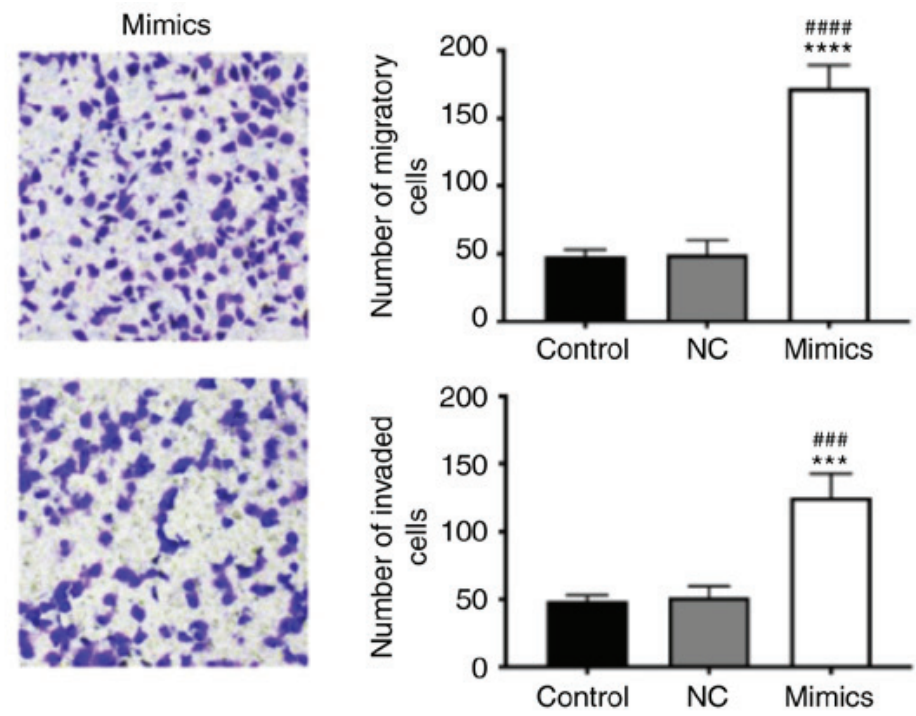

Inhibitor
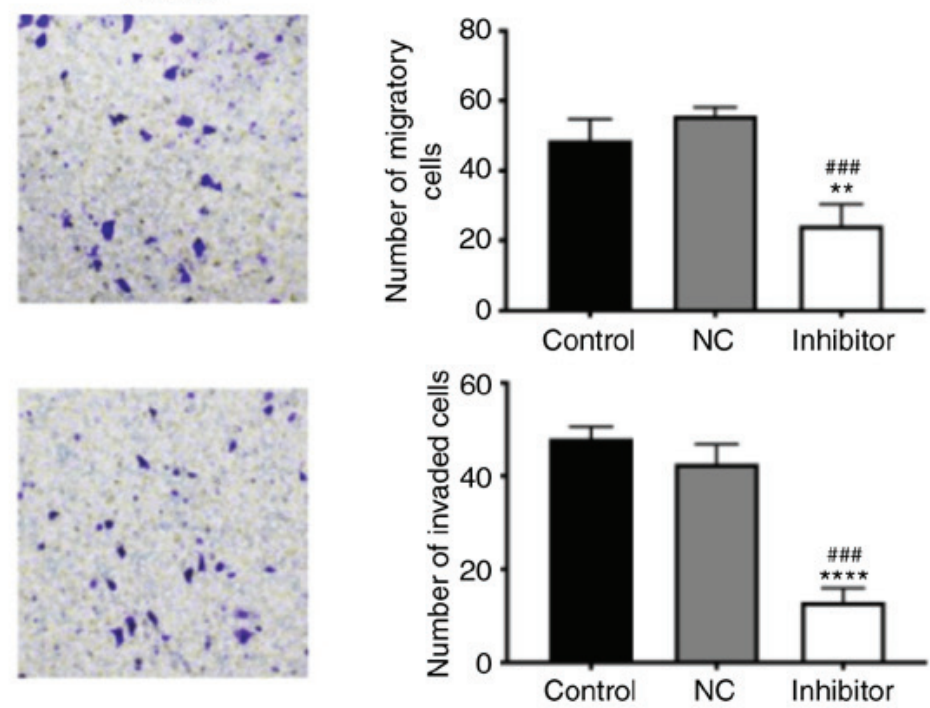

Figure 5. Upregulating the expression of miR-21 in macrophages can promote T24 cell migration and invasion. (A) The cell migration and invasion of T24 cells treated with macrophages transfected with miR-21-5p mimics were assessed by Transwell and Matrigel assays. Magnification, x100. (B) Effects of macrophages transfected with miR-21-5p inhibitor on T24 cell migration and invasion. Magnification, $\mathrm{x} 100 . \mathrm{n}=3$. ${ }^{* *} \mathrm{P}<0.01,{ }^{* * *} \mathrm{P}<0.001,{ }^{* * * *} \mathrm{P}<0.0001 \mathrm{vs}$. control group; ${ }^{\# \#} \mathrm{P}<0.001,{ }^{\# \# \#} \mathrm{P}<0.0001$ vs. NC group. miR-21, microRNA-21; NC, negative control.

PI3K/AKT-STAT3 is upregulated following the suppression of PTEN in macrophages. Notably, STAT3 activation is essential for differentiation of macrophages into the M2 phenotype (8). A previous report suggested that STAT3 activation is dependent on activation of the PI3K/AKT pathway in macrophages (29). Therefore, PI3K/AKT signalling and STAT3 signalling were next in the exo-treated and untreated groups, by assessing AKT and STAT3 phosphorylation by western blot analysis. The expression of p-AKT and p-STAT3 was greater in exo-treated macrophages than in untreated macrophages (Fig. 6G). Moreover, it was observed that the phosphorylation of AKT and STAT3 in macrophages co-cultured with anti-miR-21-5p T24 cells was lower than that in macrophages co-cultured with T24 cells (Fig. 6H). It was hypothesized that miR-21 affects macrophage polarization via the STAT3 pathway. To test this hypothesis, STAT3 phosphorylation status after treatment with miR-21-5p mimics and miR-21-5p inhibitor was analysed, and STAT3 activation was assessed. In macrophages, the introduction of miR-21-5p mimics enhanced p-AKT and p-STAT3, while introduction of miR-21-5p inhibitor attenuated these changes (Fig. 6I). Taken together, these data suggest that miR-21 directly downregulates PTEN and further enhances PI3K/AKT-induced STAT3 signalling activity.

\section{Discussion}

The present study found that bladder cancer cells express significantly higher levels of miR-21 compared with M0 macrophages, and that exosomal miR-21 transfer from bladder cancer cells to M0 macrophages can enable increases in bladder cancer cell migration and invasion through downregulation of the direct miR-21 target PTEN.

The THP-1 human acute monocytic leukaemia cell line is the cell line most commonly used to study monocyte/macrophage differentiation and function (30). However, the cell line 

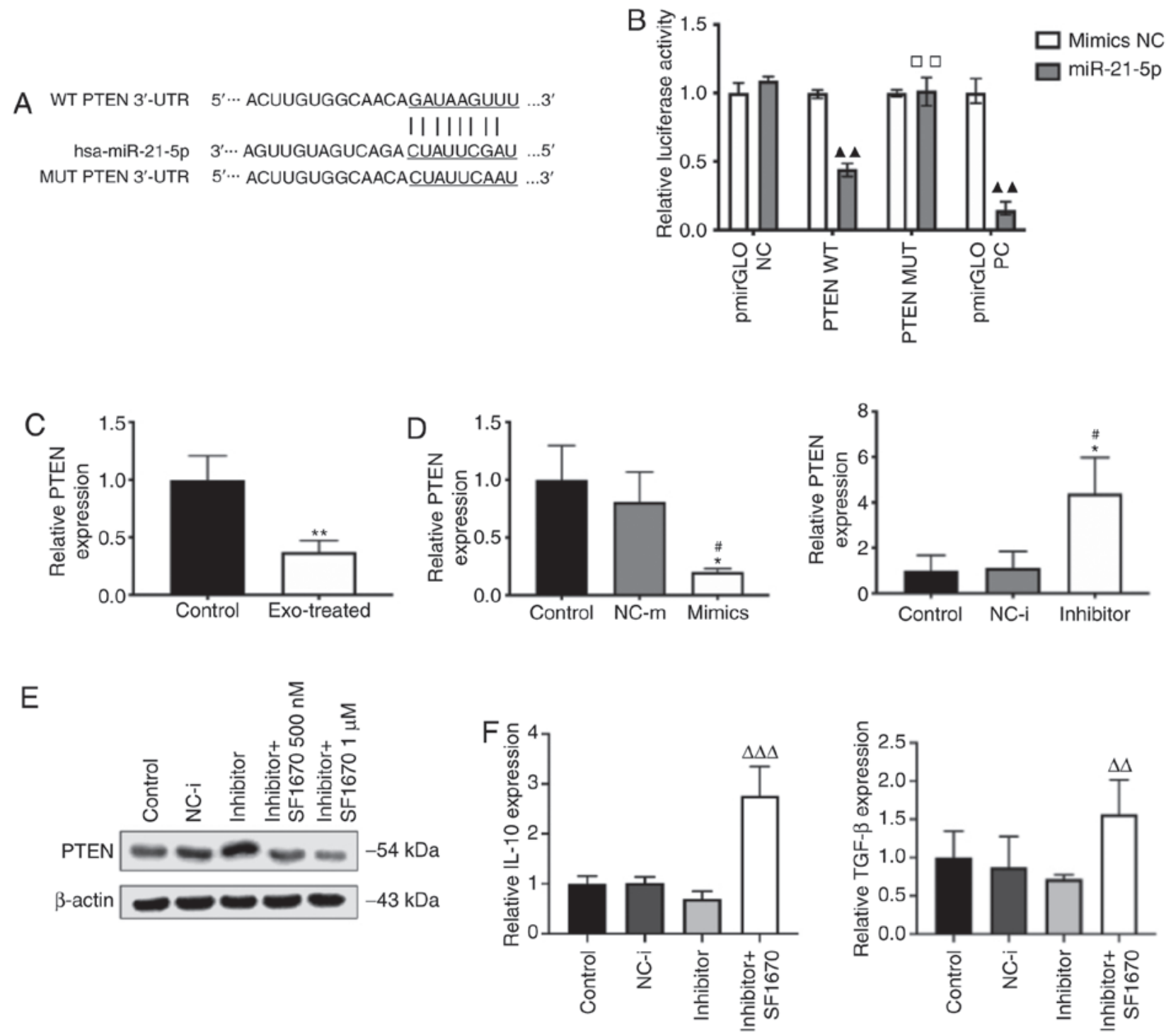

Figure 6. miR-21 downregulates PTEN expression and activates PI3K/AKT-mediated STAT3 signalling pathways in macrophages. (A) The binding site of miR-21-5p in the PTEN 3'-UTR was predicted with TargetScan. (B) M0 macrophages were transfected with either WT or MUT PTEN coding sequence vectors. Luciferase activity was measured $24 \mathrm{~h}$ after transfection. (C) mRNA levels of PTEN in macrophages treated with exosomes. (D) PTEN expression of macrophages transfected with miR-21-5p mimics or miR-21-5p inhibitor. (E) The PTEN inhibitor SF1670 $(1 \mu \mathrm{M})$ inhibited the expression of PTEN in macrophages transfected with miR-21-5p inhibitor. (F) The levels of IL-10 and TGF- $\beta$ were increased in miR-21 inhibitor-transfected cells treated with SF1670 $(1 \mu \mathrm{M})$.

THP-1 has been found to contain a mutation in the N-RAS gene (31). Mutations in the N-RAS gene cause certain structural changes in RAS proteins, which lead to inactivation and continue to stimulate cell growth or differentiation. The present study predominantly investigated the relationship between T24 cells and macrophages, so macrophages were the main experimental object rather than THP-1 cells, which were only used to induce the formation of macrophages in the present study. To determine whether the N-RAS gene mutations will interfere with our experiment, we only need to observe whether the THP-1 cells with N-RAS gene mutations can be induced to differentiate into macrophages. We found that M0 macrophages were successfully obtained from THP-1 cells after stimulation with PMA for $24 \mathrm{~h}$. Therefore, it was confirmed that the N-RAS gene mutations in the cell line THP-1 does not affect PMA-induced THP-1 cell differentiation into macrophage-like cells.
Accumulating evidence has shown that TAMs are closely related to tumour progression and metastasis through intercellular communication with cancer cells $(32,33)$. A recent study has also highlighted the roles of exosomes in the regulation of TME (34). Such regulation may result from exosome-induced effects on macrophages and phenotypic changes due to alterations in chemokines levels (35). The present study has shown that exosomes are capable of polarizing M0 macrophages into the M2-like phenotype, as demonstrated by the production of specific cytokines and the phenotypic changes in surface markers. Moreover, the present data showed that macrophages treated with non-exo CM could not be polarized into the M2-like phenotype. These results suggest that cancer cell-derived exosomes, rather than other substances outside the exosomes, activate the polarization programme in macrophages. The polarization of macrophages into the M2-like phenotype can be triggered by multiple signals. 

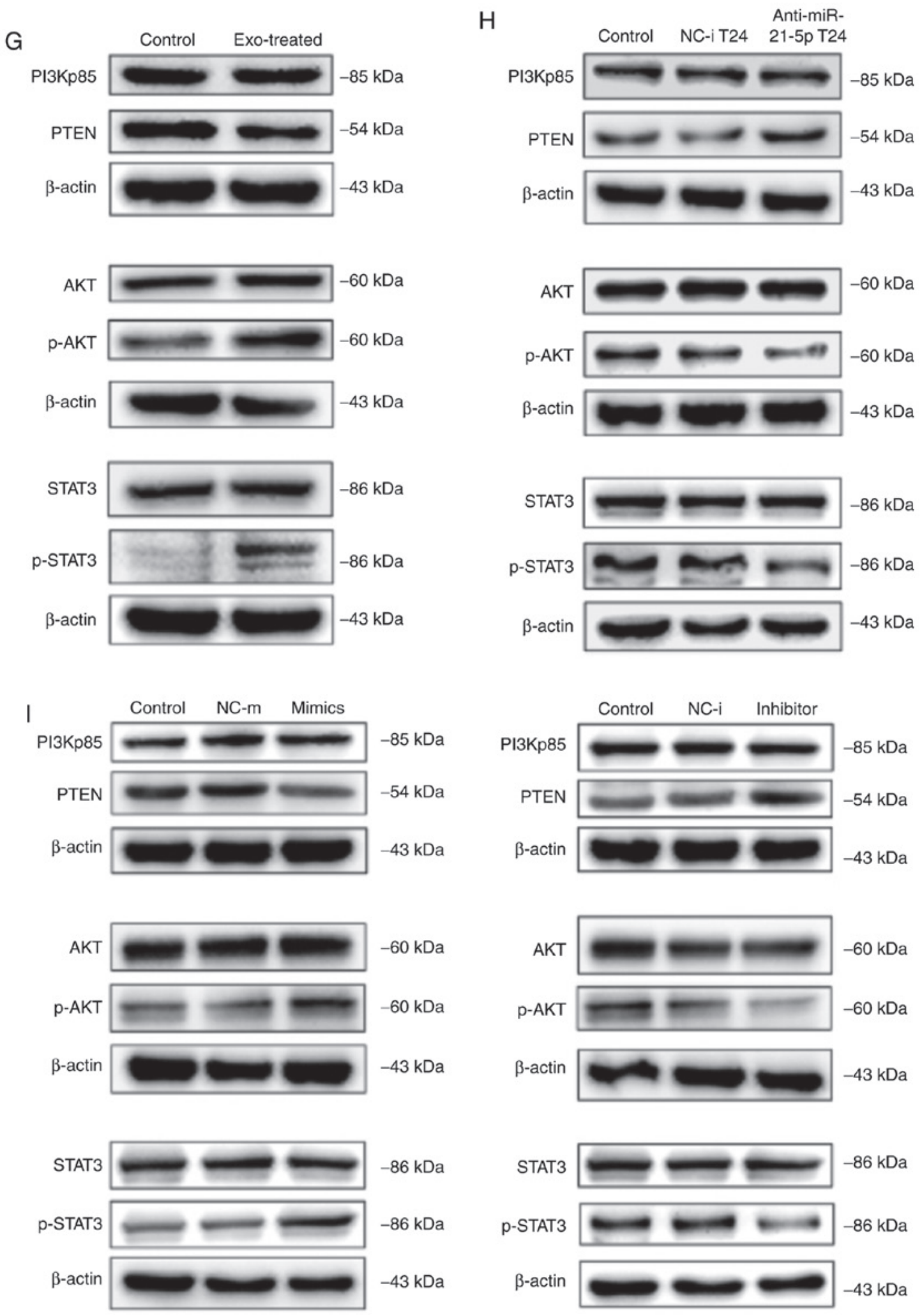

Figure 6. Continued. miR-21 downregulates PTEN expression and activates PI3K/AKT-mediated STAT3 signalling pathways in macrophages. (G) The expression of PTEN, PI3K, p-AKT and p-STAT3 in exo-treated macrophages was assessed by western blot analysis. (H) Differences in the expression of PTEN, PI3K, p-AKT and p-STAT3 between macrophages co-cultured with T24 cells and those co-cultured with anti-miR-21-5p T24 cells. (I) Expression of PTEN, PI3K, p-AKT and p-STAT3 in macrophages transfected with miR-21-5p mimics or miR-21-5p inhibitor. $\mathrm{n}=3 .{ }^{\mathbf{\Delta} \boldsymbol{\Delta}} \mathrm{P}<0.01$ vs. mimics NC group. ${ }^{\square} \mathrm{P}<0.01$ vs. PTEN WT miR-21-5p group. ${ }^{*} \mathrm{P}<0.05,{ }^{* *} \mathrm{P}<0.01$ vs. control group. ${ }^{\#} \mathrm{P}<0.05$ vs. $\mathrm{NC}$ group. ${ }^{\Delta \Delta} \mathrm{P}<0.01,{ }^{\Delta \Delta \Delta} \mathrm{P}<0.001$ vs. inhibitor group. miR-21, microRNA-21; pmirGLO NC, pmirGLO negative control; pmirGLO PC, pmirGLO positive control; NC, negative control; MUT, mutated; PTEN, phosphatase and tensin homolog; exo, exosome; p-, phosphorylated; 3'-UTR, 3'-untranslated region.

miRNA-mediated TAM regulation is one of the most studied topics in the field of TAM-related carcinogenesis. Numerous studies have investigated the effects of exosomal miRNAs on TAM functions, including macrophage polarization (36-38). 
Previous studies have shown that miR-21 is often overexpressed in different types of human cancer, including non-small cell lung cancer, colorectal cancer (CRC) and breast cancer (39-41). Notably, miR-21 expression is not significantly different between bladder cancer and normal urothelial tissues, but high expression of miR-21 is associated with poor overall bladder cancer survival and is a good indicator of metastasis (42). Moreover, among numerous miRNAs, miR-21 has been found to be overexpressed in bladder cancer tissue, urine exosomes and white blood cells (43). This evidence suggests that miR-21 can be used as a prognostic marker for bladder tumour metastasis. A recent study has shown that certain miRNAs are selectively loaded or retained in exosomes, indicating apparent exosomal enrichment of certain miRNAs compared with most cellular miRNAs (44). The present study found that miR-21 was enriched in T24 cell-derived exosomes isolated by ultracentrifugation. Furthermore, miR-21 could be transferred by exosomes from bladder cancer cells to macrophages and subsequently promote tumour migration and invasion, suggesting that the increased miR-21 expression in M0 macrophages may confer a more aggressive phenotype in these cells. miR-21 expression has been associated with M2 macrophages characterized by elevated IL-10 protein levels (45). Upon incubating M0 macrophages with bladder cancer cells, the present study confirmed that the M2 macrophage markers were significantly upregulated. In addition, the changes in cytokine markers in the macrophages were blocked by co-culturing miR-21 inhibitor-transfected bladder cancer cells with M0 macrophages in vitro. This blockade was probably due to the higher endogenous miR-21 expression in bladder cancer cells than in M0 macrophages, as confirmed by RT-qPCR analyses. Therefore, the aforementioned evidence may explain why T24 cell-derived exosomes enriched with miR-21 induce M2 differentiation. Notably, a recent study reported that M2 macrophage-regulated CRC cell migration and invasion are dependent on M2 macrophage-derived exosomes, which display high expression levels of miR-21-5p and miR-155-5p, and that exosome-mediated CRC cell migration and invasion depended on these two miRNAs (46). Thus, exosomal miR-21 seems to be able to participate in the formation of the TME and play a significant role in subsequent cancer cell migration and invasion.

The present study also demonstrated, to the best of our knowledge, for the first time, that downregulation of miR-21 in macrophages can block polarization of M0 macrophages into M2 macrophages. In the context of cancer cells with genetic defects, miR-21 can promote the polarization of macrophages into the M1-like phenotype (47). Thus, miR-21 plays a key role in directing macrophage differentiation. Additionally, it was revealed that miR-21 overexpression in M0 macrophages can induce STAT3 expression and that inhibition of miR-21 abolishes this effect. Furthermore, it was found that miR-21 inhibitor-induced STAT3 upregulation could be eliminated by SF1670, showing the dependence of this STAT3 upregulation on PI3K/AKT activation. The PI3K/AKT pathway is an upstream signalling pathway of $\mathrm{NF}-\kappa \mathrm{B}$ and can activate NF- $\kappa \mathrm{B}$ in macrophages (48). A study has shown that enhancing the $\mathrm{NF}-\kappa \mathrm{B}$ signalling pathway in macrophages can upregulate IL- 6 production and secretion in cells (49). Furthermore, blocking NF- $\kappa \mathrm{B}$ activation inhibits
IL-6 expression in macrophages (48). Recently, it has been suggested that IL-6 and STAT3 play key roles in the progression of ovarian cancer, possibly by polarizing TAMs (50). The findings of previous studies regarding the relationships among the PI3K/AKT/NF-кB/STAT3 signalling pathways can explain the phenomenon of STAT3 upregulation by exosomal miR-21 in PMA-induced THP-1 human macrophages. Regarding miR-21-induced signalling, a previous study has indicated that the STAT3 pathway is the major upstream pathway of miR-21 in monocytes/macrophages (51). Thus, the exact molecular interactions by which miR-21 induces STAT3 expression need further exploration.

Despite its successes, the present study has limitations. Given the highly invasive nature of T24 cells, the experiment revealed changes only in this one bladder cancer cell line. Different levels of invasiveness of bladder cancer cell lines can reflect differences in the influences of exosomes of different stages of bladder cancer on the polarization of macrophages. This phenomenon requires further study.

In conclusion, exosomal miR-21 derived from T24 cells could elevate the expression of M2-type characteristic genes in macrophages to further promote the invasion and migration of bladder cancer cells. However, these findings do not exclude the roles of other exosomal cargo molecules derived from cancer cells.

\section{Acknowledgements}

Not applicable.

\section{Funding}

This study was supported by a grant from the Foundation of Chongqing Science and Technology Commission (grant no. cstc2015shmszx0466).

\section{Availability of data and materials}

The datasets generated and/or analysed during the present study are available from the corresponding author upon reasonable request.

\section{Authors' contributions}

FL, WH and XG designed the experiments. FL and HY analysed the data. FL, XL and GZ performed the experiments. XG revised the manuscript. WH prepared the figures. FL wrote the paper. All authors read and approved the final manuscript.

\section{Ethics approval and consent to participate}

Not applicable.

\section{Patient consent for publication}

Not applicable.

\section{Competing interests}

The authors declare that they have no competing interests. 


\section{References}

1. Siegel RL, Miller KD and Jemal A: Cancer statistics, 2018. CA Cancer J Clin 68: 7-30, 2018.

2. Franzen CA, Simms PE, Van Huis AF, Foreman KE, Kuo PC and Gupta GN: Characterization of uptake and internalization of exosomes by bladder cancer cells. Biomed Res Int 2014: 619829, 2014.

3. Ghafouri-Fard S, Nekoohesh L and Motevaseli E: Bladder cancer biomarkers: Review and update. Asian Pac J Cancer Prev 15 2395-2403, 2014.

4. Tkach M and Théry C: Communication by extracellular vesicles: Where we are and where we need to go. Cell 164: 1226-1232, 2016.

5. Zhang $X$, Yuan X, Shi H, Wu L, Qian $H$ and $X u$ W: Exosomes in cancer: Small particle, big player. J Hematol Oncol 8: 83, 2015.

6. Kucharzewska P and Belting M: Emerging roles of extracellular vesicles in the adaptive response of tumour cells to microenvironmental stress. J Extracell Vesicles 2, 2013.

7. EL Andaloussi S, Mäger I, Breakefield XO and Wood MJ Extracellular vesicles: Biology and emerging therapeutic opportunities. Nat Rev Drug Discov 12: 347-357, 2013.

8. Sica A and Bronte V: Altered macrophage differentiation and immune dysfunction in tumor development. J Clin Invest 117: $1155-1166,2007$

9. Mantovani A, Marchesi F, Porta C, Sica A and Allavena P. Inflammation and cancer: Breast cancer as a prototype. Breast 16 (Suppl 2): S27-S33, 2007

10. Cortés M,Sanchez-MoralL, de Barrios O,Fernández-Aceñero MJ, Martínez-Campanario MC, Esteve-Codina A, Darling DS, Győrffy B, Lawrence T, Dean DC and Postigo A: Tumor-associated macrophages (TAMs) depend on ZEB1 for their cancer-promoting roles. EMBO J 36: 3336-3355, 2017

11. Cassetta L and Pollard JW: Targeting macrophages: Therapeutic approaches in cancer. Nat Rev Drug Discov 17: 887-904, 2018.

12. Aldo PB, Craveiro V, Guller S and Mor G: Effect of culture conditions on the phenotype of THP-1 monocyte cell line. Am J Reprod Immunol 70: 80-86, 2013.

13. Qin Z: The use of THP-1 cells as a model for mimicking the function and regulation of monocytes and macrophages in the vasculature. Atherosclerosis 221: 2-11, 2012.

14. Baietti MF, Zhang Z, Mortier E, Melchior A, Degeest G, Geeraerts A, Ivarsson Y, Depoortere F, Coomans C, Vermeiren E, et al: Syndecan-syntenin-ALIX regulates the biogenesis of exosomes. Nat Cell Biol 14: 677-685, 2012.

15. Zhou L, Shen LH, Hu LH, Ge H, Pu J, Chai DJ, Shao Q, Wang L, Zeng JZ and $\mathrm{He} \mathrm{B}$ : Retinoid $\mathrm{X}$ receptor agonists inhibit phorbol-12-myristate-13-acetate (PMA)-induced differentiation of monocytic THP-1 cells into macrophages. Mol Cell Biochem 335: 283-289, 2010

16. Lobb RJ, Becker M, Wen SW, Wong CSF, Wiegmans AP, Leimgruber A and Möller A: Optimized exosome isolation protocol for cell culture supernatant and human plasma. J Extracell Vesicles 4: 27031, 2015.

17. Mehdiani A, Maier A, Pinto A, Barth M, Akhyari P and Lichtenberg A: An innovative method for exosome quantification and size measurement. J Vis Exp: 50974, 2015.

18. Helwa I, Cai J, Drewry MD, Zimmerman A, Dinkins MB, Khaled ML, Seremwe M, Dismuke WM, Bieberich E, Stamer WD, et al: A comparative study of serum exosome isolation using differential ultracentrifugation and three commercial reagents. PLoS One 12: e0170628, 2017.

19. Livak KJ and Schmittgen TD: Analysis of relative gene expression data using real-time quantitative PCR and the 2(-Delta Delta C(T)) method. Methods 25: 402-408, 2001.

20. Park EK, Jung HS, Yang HI, Yoo MC, Kim C and Kim KS: Optimized THP-1 differentiation is required for the detection of responses to weak stimuli. Inflamm Res 56: 45-50, 2007.

21. Fuhrman B, Partoush A, Volkova N and Aviram M: Ox-LDL induces monocyte-to-macrophage differentiation in vivo: Possible role for the macrophage colony stimulating factor receptor (M-CSF-R). Atherosclerosis 196: 598-607, 2008

22. Park SY, Lee SW, Kim HY, Lee SY, Lee WS, Hong KW and Kim CD: SIRT1 inhibits differentiation of monocytes to macrophages: Amelioration of synovial inflammation in rheumatoid arthritis. J Mol Med (Berl) 94: 921-931, 2016.

23. Whiteside TL: Exosomes and tumor-mediated immune suppression. J Clin Invest 126: 1216-1223, 2016.
24. Italiani P and Boraschi D: From monocytes to M1/M2 macrophages: Phenotypical vs. functional differentiation. Front Immunol 5: 514, 2014

25. Martinez FO and Gordon S: The M1 and M2 paradigm of macrophage activation: Time for reassessment. F1000Prime Rep 6: 13, 2014.

26. Ohno R, Uozaki H, Kikuchi Y, Kumagai A, Aso T, Watanabe M, Watabe S, Muto S and Yamaguchi R: Both cancerous miR-21 and stromal miR-21 in urothelial carcinoma are related to tumour progression. Histopathology 69: 993-999, 2016.

27. Yue S, Rao J, Zhu J, Busuttil RW, Kupiec-Weglinski JW, Lu L, Wang X and Zhai Y: Myeloid PTEN deficiency protects livers from ischemia reperfusion injury by facilitating M2 macrophage differentiation. J Immunol 192: 5343-5353, 2014.

28. Li Y, Prasad A, Jia Y, Roy SG, Loison F, Mondal S, Kocjan P, Silberstein LE, Ding S and Luo HR: Pretreatment with phosphatase and tensin homolog deleted on chromosome 10 (PTEN) inhibitor SF1670 augments the efficacy of granulocyte transfusion in a clinically relevant mouse model. Blood 117: 6702-6713, 2011.

29. Tacke RS, Tosello-Trampont A, Nguyen V, Mullins DW and Hahn YS: Extracellular hepatitis C virus core protein activates STAT3 in human monocytes/macrophages/dendritic cells via an IL-6 autocrine pathway. J Biol Chem 286: 10847-10855, 2011

30. Chanput W, Mes JJ and Wichers HJ: THP-1 cell line: An in vitro cell model for immune modulation approach. Int Immunopharmacol 23: 37-45, 2014.

31. Sheng XM, Kawamura M, Ohnishi H, Ida K, Hanada R, Kojima S, Kobayashi M, Bessho F, Yanagisawa M and Hayashi Y: Mutations of the RAS genes in childhood acute myeloid leukemia, myelodysplastic syndrome and juvenile chronic myelocytic leukemia. Leuk Res 21: 697-701, 1997.

32. Franklin RA, Liao W, Sarkar A, Kim MV, Bivona MR, Liu K, Pamer EG and Li MO: The cellular and molecular origin of tumor-associated macrophages. Science 344: 921-925, 2014.

33. Xu H, Lai W, Zhang Y, Liu L, Luo X, Zeng Y, Wu H, Lan Q and Chu Z: Tumor-associated macrophage-derived IL-6 and IL-8 enhance invasive activity of LoVo cells induced by PRL-3 in a KCNN4 channel-dependent manner. BMC Cancer 14: 330 , 2014.

34. Berchem G, Noman MZ, Bosseler M, Paggetti J, Baconnais S, Le Cam E, Nanbakhsh A, Moussay E, Mami-Chouaib F, Janji B and Chouaib S: Hypoxic tumor-derived microvesicles negatively regulate NK cell function by a mechanism involving TGF- $\beta$ and miR23a transfer. Oncoimmunology 5: e1062968, 2016.

35. Jang JY, Lee JK, Jeon YK and Kim CW: Exosome derived from epigallocatechin gallate treated breast cancer cells suppresses tumor growth by inhibiting tumor-associated macrophage infiltration and M2 polarization. BMC Cancer 13: 421, 2013.

36. Chen X, Ying X, Wang X, Wu X, Zhu Q and Wang X: Exosomes derived from hypoxic epithelial ovarian cancer deliver microRNA-940 to induce macrophage M2 polarization. Oncol Rep 38: 522-528, 2017.

37. Park JE, Dutta B, Tse SW, Gupta N, Tan CF, Low JK, Yeoh KW, Kon OL, Tam JP and Sze SK: Hypoxia-induced tumor exosomes promote M2-like macrophage polarization of infiltrating myeloid cells and microRNA-mediated metabolic shift. Oncogene 38: 5158-5173, 2019

38. Wang X, Luo G, Zhang K, Cao J, Huang C, Jiang T, Liu B, Su L and Qiu Z: Hypoxic tumor-derived exosomal miR-301a mediates M2 macrophage polarization via PTEN/PI3K $\gamma$ to promote pancreatic cancer metastasis. Cancer Res 78: 4586-4598, 2018.

39. Markou A, Sourvinou I, Vorkas PA, Yousef GM and Lianidou E Clinical evaluation of microRNA expression profiling in non small cell lung cancer. Lung Cancer 81: 388-396, 2013.

40. Chen TH, Chang SW, Huang CC, Wang KL, Yeh KT, Liu CN, Lee H, Lin CC and Cheng YW: The prognostic significance of APC gene mutation and miR-21 expression in advanced-stage colorectal cancer. Colorectal Dis 15: 1367-1374, 2013.

41. Si ML, Zhu S, Wu H, Lu Z, Wu F and Mo YY: miR-21-mediated tumor growth. Oncogene 26: 2799-2803, 2007.

42. Zaravinos A, Radojicic J, Lambrou GI, Volanis D, Delakas D, Stathopoulos EN and Spandidos DA: Expression of miRNAs involved in angiogenesis, tumor cell proliferation, tumor suppressor inhibition, epithelial-mesenchymal transition and activation of metastasis in bladder cancer. J Urol 188: 615-623, 2012.

43. Armstrong DA, Green BB, Seigne JD, Schned AR and Marsit CJ: MicroRNA molecular profiling from matched tumor and bio-fluids in bladder cancer. Mol Cancer 14: 194, 2015. 
44. Mittelbrunn M, Gutiérrez-Vázquez C, Villarroya-Beltri C González S, Sánchez-Cabo F, González MÁ, Bernad A and Sánchez-Madrid F: Unidirectional transfer of microRNA-loaded exosomes from $\mathrm{T}$ cells to antigen-presenting cells. Nat Commun 2: 282, 2011.

45. Caescu CI, Guo X, Tesfa L, Bhagat TD, Verma A, Zheng D and Stanley ER: Colony stimulating factor-1 receptor signaling networks inhibit mouse macrophage inflammatory responses by induction of microRNA-21. Blood 125: e1-e13, 2015.

46. Lan J, Sun L, Xu F, Liu L, Hu F, Song D, Hou Z, Wu W, Luo X, Wang J, et al: M2 macrophage-derived exosomes promote cell migration and invasion in colon cancer. Cancer Res 79: 146-158, 2019.

47. Xi J, Huang Q, Wang L, Ma X, Deng Q, Kumar M, Zhou Z, Li L, Zeng Z, Young KH, et al: miR-21 depletion in macrophages promotes tumoricidal polarization and enhances PD-1 immunotherapy. Oncogene 37: 3151-3165, 2018.

48. Guo W, Sun J, Jiang L, Duan L, Huo M, Chen N, Zhong W, Wassy L, Yang Z and Feng H: Imperatorin attenuates LPS-induced inflammation by suppressing NF- $\mathrm{B}$ and MAPKs activation in RAW 264.7 macrophages. Inflammation 35: 1764-1772, 2012.
49. Wang YC, Hu YW, Sha YH, Gao JJ, Ma X, Li SF, Zhao JY, Qiu YR, Lu JB, Huang C, et al: Ox-LDL upregulates IL-6 expression by enhancing NF- $\kappa \mathrm{B}$ in an IGF2-dependent manner in THP-1 macrophages. Inflammation 38: 2116-2123, 2015.

50. Ham S, Lima LG, Chai EPZ, Muller A, Lobb RJ, Krumeich S, Wen SW, Wiegmans AP and Möller A: Breast cancer-derived exosomes alter macrophage polarization via gp130/STAT3 signaling. Front Immunol 9: 871, 2018.

51. Iliopoulos D, Jaeger SA, Hirsch HA, Bulyk ML and Struhl K: STAT3 activation of miR-21 and miR-181b-1 via PTEN and CYLD are part of the epigenetic switch linking inflammation to cancer. Mol Cell 39: 493-506, 2010.

This work is licensed under a Creative Commons Attribution-NonCommercial-NoDerivatives 4.0 International (CC BY-NC-ND 4.0) License. 